\title{
In-between access and transformation: Analysing a university writing centre's academic support programme for education students as third space
}

\author{
Halima Namakula \\ University of the Witwatersrand, South Africa \\ E-mail: hknamakula@gmail.com \\ Maria Prozesky \\ Division of Languages, Literacies and Literatures, University of the Witwatersrand \\ E-mail: maria.prozesky@wits.ac.za
}

\begin{abstract}
This paper reports on ongoing research into how an embedded academic support programme, based in a South African university's writing centre, shapes the academic literacy practices of first-year B.Ed. students. This paper focuses specifically on the peer tutors who implement the programme. Our data collection and analysis methods are informed by socio-cultural theories of literacy and the notion of 'discursive third space'. The tutors' discursive reconstructions of the intervention programme are understood to reveal the dynamics of how the intervention functions as third space. Peer tutors were selected purposefully for the study; they needed to have had at least one year of experience tutoring and mentoring in the intervention programme, and five peer tutors agreed to take part. Data was collected using an audio-recorded focus-group interview, and the transcription analysed; data was coded into meaning units within which key themes, patterns, and categories informed by the study's theoretical frameworks were identified in a recursive process. The analysis reveals that the tutors use the intervention programme as a third space in which they draw on the students' varied "funds of knowledge and Discourse" (Moje, Ciechanowski, Kramer, Ellis, Carillo and Collazo 2004), with three main results evident. Firstly, because the students' learning is scaffolded, and their skills in navigating between different spaces, Discourses, and funds improved, their epistemological access to dominant Discourses around academic literacy and course content increases. Secondly, the tutorial third space offers potential for reshaping dominant Discourses, and so for decolonial transformation. Thirdly, however, the strain of working in-between competing funds of knowledge can be inhibiting rather than generative, resulting in "post-colonial splitting" (Bhabha 1994). If we are to engage meaningfully with the academic-support access paradox, the insights that the tutorial third space generates have to be taken seriously.
\end{abstract}

Keywords: access to higher education, academic literacy, third space, peer tutors, decolonial transformation 


\section{Introduction}

The writing centre, as part of a university's academic support structure, is always an "inbetween" place. Carter (2009: 136) explains why:

The writing centre is made up of a series of rhetorical spaces in which tutors and students attempt to negotiate academic projects assigned by and evaluated by individuals who are not directly associated with/involved in the writing centre's daily activities. We represent the student, not the teacher. We represent the system, not the student. We represent neither, and we represent both.

This in-between character is heightened when a writing centre employs senior students to tutor their less-experienced peers in academic literacies because these peer tutors are at once part of the student body and part of the academic structure. In this paper, we draw on the perceptions of a sample of peer tutors who work in an academic literacy intervention programme, called "Write Up Read Up" (WURU), hosted by the writing centre on the education campus of a large public university in Johannesburg, South Africa. The tutors' perceptions, their discursive reconstruction of the intervention, reveal that the tutorial space functions as third space, that is, a hybrid discursive space constituted by several competing Discourses ${ }^{1}$. In the WURU tutorials, the first of these competing Discourses is what we will call the "dominant Discourses of academia" which, as Archer (2012) explains; include "dominant languages, varieties, and discourses, modes of representation, genres and types of knowledge". These dominant Discourses co-exist alongside the unofficial, everyday Discourses of the students, with their various home cultures, religious and political investments, and socio-economic situations. At the interface of these Discourses, some important tensions are revealed between competing theories around whether academic literacy is a set of neutral skills or of complex social practices, and between the students' various positionalities in terms of possessing or lacking academic literacy. We argue that this "in-betweenness" of the peer-led writing-centre tutorial space can be an empowering resource not only for student learning, but also for the decolonial transformation of the university.

The academic support space, because it is shaped directly by competing discourses around academic knowledges and Discourses, and because it is a site where marginalised students engage directly with dominant academic literacies, positionalities, and ways of knowing, is arguably a uniquely promising place to observe some of their more direct negotiations around these dominant Discourses. We show that in the peer-led tutorials under study, the students are bringing their various cultural resources into productive interaction, with results that not only promote learning by enabling epistemological access, but also suggest ways forward in destabilising the hegemonic claims of dominant academic Discourses. We also uncover significant ways in which this nascent transformation is impeded by what Janks (2004: 33) identifies as an "access paradox": "If you provide more people with access to the dominant variety of the dominant language, you contribute to perpetuating and increasing its dominance. If, on the other hand, you deny students access, you perpetuate their marginalisation in a society that continues to recognise this language as a mark of distinction".

\footnotetext{
${ }^{1}$ Following Gee (1996: 131), we distinguish between a "big-D" Discourse, which is "a socially accepted association among ways of using language, other symbolic expressions, and artifacts, of thinking, feeling, believing, valuing and acting that can be used to identify oneself as a member of a socially meaningful group or "social network", and a "small-d" discourse, which is language in use, a much more circumscribed notion.
} 
In the sections that follow, we first contextualise the study within the broader history of academic support in South Africa, and second, briefly discuss third-space theory as applied to education, to provide our theoretical framework. Third, we describe the WURU intervention and the writing centre. Fourth, we present the findings of the study, setting out the ways that the tutorial third space functions as revealed through the experiences and perceptions of the peer tutors. Wilmot and McKenna (2018) argue that South African universities need new forms of student support that speak to the current transformative agenda, and are able to respond to the ever-changing needs of the diverse student body. We end with brief suggestions as to how interventions such as WURU can contribute to the development of such academic support.

\section{Academic support in South African universities: The access paradox}

The context of this study and of the analyses we present is the history of academic support in South African universities. Changes in the political space since the end of apartheid have granted previously-disadvantaged groups the opportunity to access higher education. This has brought about not only a rapid increase in student numbers, but also profound changes in the nature of the student body in terms of the diverse learning abilities and needs, cultures, and educational backgrounds that students bring into university spaces (Clarence and McKenna 2017, Wilmot and McKenna 2018, Wingate 2006). These changes happening in university spaces have challenged both universities and students (Wingate 2006). Research has shown that a large proportion of students are underprepared to engage successfully with the academic demands of their disciplines (Carstens 2013, Paxton 2007, Wingate and Dreiss 2009) in terms of literacy and numeracy (Carstens 2013, Widin 2018, Wingate 2015), and academic literacies (Butler 2013, Van Schalkwyk 2008). Initially, support programmes took the form of generic academic literacy courses premised on an autonomous model of literacy as a set of neutral, technical "skills" (Street 2003). Previously-disadvantaged students were seen as "lacking" these skills, and in this way were constructed by "deficit discourses" as an integral part of the problem which hindered their learning (see Boughey 2002, Coleman 2016, Haggis 2003, Widin 2018, Wingate 2015, Wingate and Dreiss 2009). These generic courses tended to be situated at the periphery of university structures and divorced from academic disciplines (Boughey and McKenna 2016; Wilmot and McKenna 2018; Wingate 2006, 2009). More recently across South African universities, however, recognition has grown that literacy is a historically-informed socio-cultural practice (Street 2003) which implies that when students enter university, they are required to take on not a set of neutral skills but rather a network of powerful Discourses. Academic support involves helping students negotiate this complex discursive space so as to help ensure that they gain not only "formal" access to higher education but, more importantly, "epistemological" access, which is access to these socio-culturally situated ways of knowing and being which sustain the academy (Morrow 1994).

It is not clear how to achieve epistemological access most effectively at South African universities, however, given that "the academic practices that are valued in these institutions have generally remained constant, and English as the medium-of-instruction continues to dominate across educational levels in South Africa" (Council on Higher Education 2016, as cited in Wilmot and McKenna 2018: 2). The core of the access problem is not the "underprepared" student so much as the inflexibility and monocultural bias of the university's Discourses. Yet South African academic spaces cannot be divorced from wider global networks of Discourse and practice that both exceed and permeate our local institutions' boundaries. This 
makes epistemological decolonisation of universities a complex problem with the access paradox at its heart. As Archer (2012: 356) explains, there are powerful "social, educational, and political advantages of acculturation into university practices. If students are denied access, their marginalisation is perpetuated in a society [like South Africa's] that values these practices". The social mobility that a university degree can help ensure is a strong deterrent to critical questioning of the dominant Discourses that underpin this degree. Therefore, as Archer (2012: 356) continues, "socialisation into dominant practices contributes to maintaining their dominance and can uncritically perpetuate the status quo".

Both sides of this access paradox can be seen shaping academic support structures in South African universities. On the one hand, universities are under immense political and public pressure to admit increasing numbers of previously-disadvantaged students, and to make sure they graduate. Institutions turn to deficit discourses around academic literacy, as they "attempt to insure themselves against the risk of low throughputs by managing 'risky' students through careful and systematic measurement" (Dison and Mendelowitz 2017: 194). At the same time, students are increasingly vocal in demanding not only greater access to higher education, and all the emancipation this offers, but also decolonisation of the university, with no clear consensus as to how the conflict between these imperatives is to be resolved (Griffiths 2019). The multiple voices, events, provocations, and responses of the \#FeesMustFall protests reveal just how complex and opaque our options currently are for the decolonial redesign of higher education. Nakata, Nakata, Keech and Bolt (2014) argue that lasting transformation must begin with an accurate understanding of the space in which non-dominant forms of knowledge and identity exist. This "indigenous knowledge space", as they call it, is a space of negotiation between persisting indigenous knowledge systems, on the one hand, and the ongoing presence of Western knowledge systems, on the other. Nakata et al. (2014) insist that in this negotiation, students from non-dominant cultures are always active agents, subjected to dominant Discourses but also monitoring their impact, often conforming to their demands but at other times "ignoring or refusing" them, or even appropriating them for "indigenous purposes and interests" (Nakata et al. 2014: 125). Decolonial reimagining of higher education should therefore begin with understanding the "complicated, embodied histories" (Nakata et al. 2014: 125) of how students from non-dominant cultures negotiate their encounters with the dominant Discourses of university. This negotiation is central to what happens in space of the WURU tutorial. To theorise this negotiation, we turn to third-space theory.

\section{Theorising third space}

Third-space theory was developed to help understand the complexity of people's everyday identities, practices, and spaces in a globalised world (see Bhabha 1994, Soja 1996). We draw on the educational perspectives on third space developed by Gutiérrez, Baquedano-López and Tejeda (1999), Gutiérrez (2008), and Moje, Ciechanowski, Kramer, Ellis, Carillo and Collazo (2004). Third space is a discursive space constituted in-between competing socio-cultural funds of Discourse and knowledge. Moje et al. (2004: 41) apply the concept to any discursive site where learning takes place, arguing that these sites are shaped by the "integration of knowledges and Discourses drawn from different spaces". Every student develops these knowledges and Discourses in what Moje et al. call "funds" (2004: 38), in other words, the community structures in which the young people take part. These funds include "homes, peer groups and other network relationships which shape the oral and written texts young people make meaning of and produce as they move from classroom to classroom and from home to peer, group, to 
school, or to the community". Whereas these funds and the Discourses they generate are often constructed in opposition to each other - for example, the "everyday" against the "academic" or "in-school" versus "out-of-school" - Moje et al. (2004: 41) see third space as a place for productively bringing together the learners' funds of knowledge, a space "that merges the 'first space' of people's home, community and peer networks with the 'second space' of the Discourses they encounter in more formalised institutions such as work, school, or church". The idea of third space as a construct of discursive space can apply to "the integration of competing knowledges and Discourses; to the text one reads and writes; to the spaces, contexts, and relationships one encounters; and even to a person's identity enactments and sense of self" (Moje et al. 2004: 42). As this paper will show, all of these elements are involved in the third space of the peer-led writing-centre tutorial.

The in-betweenness of third space implies a resistance to binaries, as noted above. The notion of third space as "in-between" several competing funds of knowledge emphasises that the goal is not to privilege one of these funds over the others, but rather to draw on them all; as English (2005: 87) suggests, the word "third" indicates "the location where negotiation occurs". Third space allows alternative and competing Discourses and positionings to transform conflict and differences into rich zones of collaboration and learning (Gutiérrez, Rymes and Larson 1995), and also of identity and ownership; third space presents a way of seeing things differently as it becomes the viewers' own space (English 2005). Third-space theory therefore has potential for guiding a critical decolonial analysis of learning spaces, and for reimagining more just alternatives.

Gutiérrez et al. (1995) therefore argue for the value of third space as a conceptual tool to help us understand how complex learning environments are and how transformative they can be. For these researchers, third space can empower students from non-dominant cultures by acting as a bridge to school-based funds of knowledge and Discourse. In this view, all the various funds of knowledge and Discourse to which students have access are constructed as resources for helping students learn by providing the "mediational context and tools necessary for future social and cognitive development" (Gutiérrez, Baquedano-López, Alvarez and Chiu 1999: 92). In other words, third space can scaffold the movement from students' first-space funds of knowledge to more conventional and authoritative third-space academic or school knowledge. Moje and her colleagues (2004) add to this understanding of third space as scaffold by arguing for two further functions that third space can perform, namely as a navigational space, and as a space of change. By navigational space, Moje et al. (2004) mean a space where students can draw on their everyday funds of knowledge to negotiate the discursive boundaries between everyday and school knowledge, and between different school disciplines (see Gee 1996). Students draw on skills learnt in one particular context to navigate across and between other multiple contexts. Lastly, Moje et al. (2004: 44) argue that third space can be a space of "cultural, social, and epistemological change in which the competing knowledges and Discourses of different spaces are brought into 'conversation' to challenge and reshape both academic content literacy practices and the knowledges and Discourses of youths' everyday lives". This third role for third space is perhaps the most difficult to achieve because it involves challenging, destabilising, and expanding the set of literacy practices "that are typically valued in school and in the everyday world" (Moje et al. 2004: 44). However, whereas the first two functions of third space, scaffolding and navigation, add most to improving students' epistemological access, it is this third function - third space as transformation space - that can directly contribute to epistemological decolonisation. 


\section{Investigating WURU: Research design and methods}

This study draws from data collected during a larger investigation of an academic support intervention implemented in 2014 by the writing centre at a public university's school of education in Johannesburg, South Africa. This larger qualitative study, which aims to describe the impact of the intervention, uses a case-study design and employs observation, individual interviews, focus-group interviews, and examination of students' work. The participants, who include peer tutors, students attending WURU, and the programme coordinator, were selected by purposive sampling; in other words, the main researcher chose them because she judged them to be typical in their "possession of the particular characterstic(s) being sought" (Cohen, Manion and Morrison 2018: 218). For this particular article, we focus on the peer tutors, and explore their experience of the intervention programme.

Peer tutors were chosen who had at least one year of experience tutoring and mentoring in the intervention programme hosted in the writing centre. Five peer tutors - four female and one male - agreed to participate in the study; three were undergraduate students, and two postgraduate students (one Masters and one $\mathrm{PhD}$ ). They are referred to below using pseudonyms to protect their anonymity, and female pronouns are used throughout to disguise the sole male participant. Our data collection and analysis methods are informed by the socio-cultural and discursive theories outlined in the preceding sections of this article. The tutors' perceptions, their discursive reconstruction of WURU, are revealing of the dynamics of how the intervention functions as a third space. Therefore data was collected using a focus-group interview conducted with the five tutors by the main researcher. This form of group interview draws not only on the words of individual participants, but also on the interaction within the group, "yielding a collective rather than an individual view" (Cohen et al. 2018: 532). The data was transcribed verbatim from audiotape immediately after the interview, and a pseudonym chosen for each participant by the researchers. Permission to carry out the study was obtained from the relevant university and government ethical councils. Analysis began with coding the data into meaning units, followed by a recursive process (as described by Wellington (2015: 263)) of identifying key themes, patterns, and categories informed by the theoretical frameworks discussed above.

The intervention programme must be described because it provides the context of the focusgroup data discussed below. The WURU intervention programme was introduced in 2014 with the aim of supporting first-year students who underperformed in the academic literacy component of the National Benchmark Test. The programme is embedded within the compulsory first-year Education Studies course, offering support in terms of reading, writing, exam preparation, and approaches to revision for the work students do in this course. WURU is administered by peer tutors who meet regularly with small tutorial groups of approximately six students to consolidate their engagement with the course materials. Though students are encouraged to attend regularly, once or sometimes twice a week, they are not prohibited from withdrawing if they wish to. The coordinators and peer tutors manage student attendance and participation, organising tutorials depending on the availability and willingness of the peer tutors who are remunerated for their work.

The tutors are senior students in the school of education, that is, second-, third- or fourth-year undergraduate students or postgraduate students in Education, who were chosen because of their academic performance (an average of $65 \%$ or more), and their commitment and desire to help fellow students. Those selected are interviewed and taken through training before they 
start tutoring. After training, peer tutors are required to observe a senior tutor for at least two weeks before they are given their own group to tutor. They are also continually provided with training throughout the year to enhance their knowledge of facilitating and mentoring students during group sessions. The tutors are given some tools such as icebreakers, worksheets, and reading and writing tools (often drawn from Education Studies content), but they are also given leeway to use their own strategies in facilitating these sessions.

The aim of the WURU intervention is to offer academic literacy support to students who are underprepared for university. This suggests that the programme was initially conceptualised in terms of deficit discourses. Yet central aspects of both the intervention's design and its implementation actually predispose the tutorial space to become a third space that draws on rather than denying the students' funds of knowledge. These aspects are the use of peer tutors, and the two-way questioning pedagogy they are trained to use. According to Dison and Mendelowitz (2017: 196), the decision was taken to use students as tutors rather than more senior staff members because the former "have an intimate knowledge of the course experience, as well as the demands of the tasks". In other words, the tutors can draw on not only the explicit fund of knowledge that is the course content, but also other second-space funds of knowledge and Discourse, including official academic literacy practices which they as senior students with good academic records have already mastered to a significant extent. Some of the peer tutors participated in WURU as first-year students themselves, so they have also experienced first-hand the acquisition of dominant Discourses. In addition, the tutors often come from the same kinds of previouslydisadvantaged background as their tutor group members, and so share marginalised first-space funds of knowledge with their students. To their in-between status as members of both the academic community and the student body are therefore added layers of complexity arising from the specific socio-historical context of the South African university, discussed in section 2 above. The design of the intervention, using peer-led tutorials, thus relies on the tutors drawing on these experiences to create opportunities for scaffolding and navigation.

The tutors are aware of their in-betweenness on some level. They describe their tutorials as an "extension" or "support" to what they call the "actual" tutorials of the Education I course. These terms give the WURU tutorial space an ambiguous status as not as official or formal as the course tutorials. The original planners of the WURU intervention did anticipate the affordances of this status by choosing to train the peer tutors not to deal with content per se, but rather to use "discovery questions" (Dison and Mendelowitz 2017: 196) to help students think critically about the decisions and choices they make in their writing. This kind of questioning works by "deconstructing and reconstructing ideas in order to construct a common understanding of the writer's meaning between the peer and the student" (Hutchings 2006: 251). The tutors and the students are both active participants in a two-way conversation which allows students to have what Archer (2011, as cited in Dison and Mendelowitz 2017: 196) calls "agency" in their learning. The freedom tutors have to supplement provided materials with pedagogies of their own also encourages them to draw on their varied funds of knowledge in the tutorial space. So in both design and implementation, the WURU program predisposes the tutoring sessions to become what Gutiérrez (2008) calls "collective third space". The shared nature of the space emphasises the collective nature of learning where participants negotiate dynamics of dependence and independence, authority and compliance, around learning outcomes and processes. In the following section, we present the findings as to what the peer tutors do with this collective third space. 


\section{Findings: In-between access and transformation}

In this section, we analyse the tutors' discursive reconstruction of the WURU tutorial space within the categories of scaffolding, navigation, and transformation which are outlined in our discussion of third-space theory above. In addition, we map an area of the tutorial third space where conflict between competing Discourses is not successfully overcome, and the students and peer tutors experience what Bhabha calls "post-colonial splitting" (1994: 98-99), that is, they simultaneously take up and resist dominant Discourses in a dynamic that is uneasy rather than generative. In the discussion below, the tutors are referred to using pseudonyms.

\subsection{Scaffolding}

The peer tutors think of the tutorial space as third space, both scaffolding and navigational, even though they do not use these terms. They speak about how the intervention acts as an induction space. Maureen mentions "induction to reading", and Kershree broadens this by saying, "Inducting them into reading and writing. I don't know if induction is the right thing but you are kind of helping them along that journey in developing those skills". Liezel agrees, commenting that the students get a chance to "interact with this academic language" which they may never have done before. The metaphors of a "journey" and an "interaction" suggest a process of gradual familiarisation through experience which involves scaffolding the students' learning in the zone of proximal development (Vygotsky 1978). The tutors also have a strong sense that their role is to act as sources of knowledge and practice, but not as directors of what the students do with these. For Kershree, a tutor must actively refrain from "impos[ing her] own views, ideas, [and] practices" because the students "need to find their own lane and develop practices. Just there to guide". Liezel also uses the word "guide", saying, "I am just a facilitator; I am just a guide". Implicit in this construction of the tutor-student relationship is dependence on the students' own funds of knowledge on which they draw as they find their way through new academic Discourses. A striking example of drawing on students' linguistic funds of knowledge is when Sharon, who is Zulu, conducts her tutorial classes in IsiZulu because it is a language with which her tutor group feels more comfortable than with English. In their scaffolding practices, significantly, the tutors do not hold themselves as superior to the students in a hierarchy of academic proficiency. In this way, they resist the positionings inherent in deficit discourses, and instead emphasise a more horizontal power dynamic.

\section{$5.2 \quad$ Navigation}

Building navigational skills assumes a significant place in the tutors' conversations. They create navigational third space for their students in two senses: firstly, in making available peer funds of knowledge which, as Gutiérrez (2008) and Moje et al. (2004) show, encompass the written and unwritten rules of not only academic work but also academic life, and, secondly, in making explicit the status of these "rules" as socially-constructed conventions. The tutors have a profound grasp of academic literacy as a multifaceted socio-cultural practice, and so of the varied skills and knowledges students have to acquire if they are to succeed at university. When asked to define academic literacy, Sharon answers, "the ability to deliver and perform according to the expectation of being a university student". She implies that academic support requires something similar to what Lea and Street $(1998,2000,2006)$ would call "academic socialisation", the process whereby students are inducted into academic "culture", by which is meant the "ways of talking, writing, thinking, and using literacy that typif[y] members of a disciplinary or subject 
area community" (Lea and Street 2006: 369). But Sharon's description of her practice extends beyond the specifically discursive space described by Lea and Street to include physical, embodied space. She recounts how at exam times, drawing on funds of embodied knowledge of the university's physical spaces and procedures, she sends her tutor group reminders via social media about dressing warmly for the cold exam venues, and bringing extra pens to exams, rather than reminding them about academic writing. Other tutors mention guiding newer students to resources such as the past exam papers available on the library website, or training them in using the university's learning-management system. In the peer-led tutorial space, therefore, the tutors make available not only "official" funds of knowledge related to academic literacy, but also what could be called more "peripheral" or "informal" funds of knowledge necessary for being a student at the school of education, on its specific Johannesburg campus. This is what Mills and Comber (2013: 412) would call "a rebalancing of the semiotic with the materiality of lived, embodied and situated experience" in our understanding of literacy.

What is significant here is not so much that the first-year students acquire this knowledge from fellow students; peers have been noted to be the major source of these unofficial knowledges and dispositions (Widin 2018: 4). More importantly, the peer fund of knowledge moves into the official university space because of the semi-official status of the peer tutors and the writing centre. There is a blurring of binaries; as Gutiérrez (2008: 152) puts it, in the third space of the tutorial, "the formal and informal, the official and unofficial spaces of the learning environment [...] intersect, creating the potential for authentic interaction and a shift in the social organisation of learning and what counts as knowledge". This intersection involves the students' first spaces of home and friendship too, as the tutors work to maintain each group as a community, for example, by forming WhatsApp groups for their members. The tutors speak of the first-years as being in a particularly vulnerable position because they are unmoored from their school-based social structures and friendships, and see the tutorial groups as compensating for this. Widin (2018) suggests that students can actually value these relationships more than the formal learning they gain in their tutorial groups, and Sharon seems to have witnessed this. She suggests the depth of the relationships that can form within groups when she says, "There is a lot of writing and reading and the improvement of those skills but at the same [time] there is also the family. When we do our last WURU session they are like, 'Ooh, I actually had a family here.' Knowing that there is help available, as a student. When, you know, 'I can actually go and call on someone"'. The third space allows students to form relationships with peers that transcend the intervention (Moje 2013), and the links this creates between different domains of life and literacy are resources for navigating academic spaces.

In addition to giving students access to these varied, unofficial peer funds, several of the tutors have also developed a second navigational tool, one which is more closely connected with official academic Discourses. This tool is explicit or implied engagement with the historicity of these dominant Discourses. In academic support programmes premised on deficit discourses, the university imposes on students the historically dominant view of what it means to be literate. As Lillis and Turner (2001: 22) explain, in this situation, "whilst the language of students is made visible and problematised, the language of the disciplines and the pedagogic practices in which these are embedded usually remains invisible, taken as 'given'". Thus, support initiatives and university Discourses are not questioned but are taken for granted and assume the role of the "truth" (Hall 1997). Two of the WURU tutors describe tutorial activities that work to make visible the usually transparent ideological underpinnings of dominant Discourses. Liezel, who cannot speak a local African language, encourages students to discuss and write in their own 
home languages when doing free writing in class. She then asks the students to translate their work into English paragraphs, after which she helps them to "make it look more academic", as she puts it. In other words, she helps the students translate their work again into acceptable academic register. In this way, Liezel not only directly engages her students' indigenous funds of knowledge to scaffold their learning, but also brings academic ways of writing into explicit discussion, revealing their nature as culturally-situated conventions. Paballo does something similar when she describes getting her group to debate "how people learn": "I would say, "what do you think?' and in that they form their own perspective, what their own views [are]". The students gain conscious insight into the workings of academic conventions which will make them more skilful in navigating between every day and academic knowledges and Discourses.

In addition, though the tutors might not discuss this explicitly, there is potential for the transformative function of third space, namely destabilising and expanding the set of literacy practices taken to be authoritative in the academic space. Having understood that the dominance of historically-Western academic Discourses is socially constructed, the students are in a position to develop an "epistemic attitude" of skepticism that opens space for considering "the delimitations and dispositions" of this Discourse, and of all discourses, as constructed (Nakata et al. 2014: 131). The tutors do not, however, discuss this transformative potential explicitly, nor even seem to be aware of it. In the examples discussed in the next section, however, the challenge mounted in the third space to dominant Discourses and positionings is more upfront.

\subsection{Transformation}

A very important way in which the tutors open a space of change is by reframing deficit discourses. The tutors begin their talk about the programme using deficit discourses, describing the students in terms of their lack of academic skills in reading, writing, and thinking. As Liezel puts it, the students "do not know how to read. They do know how to read but not those big chapter reading and also academic reading". Sharon adds that "students also fail to link one reading with the other". The tutors' use of deficit discourses suggests that such discourses are still current at the university, since they must have been taught to use them or else absorbed them indirectly by hearing them used by teaching staff. However, as the tutors' conversation deepens, they actually replot this deficit narrative, shifting the ground from lack of dominant academic knowledges and Discourses to fear of them. Certain discrete academic skills can act as bottlenecks to academic literacy because of the status they assume in the minds of the students, and therefore how they can impede the students' investment in and ownership of broader academic practices. The tutors begin to talk of the students as lacking not literacy skills but rather "confidence", by which they seem to mean, as Maureen puts it, "self-efficacy, belief that [they] can actually do this". Liezel mentions referencing specifically: "it is part of your assignment but it is also a small part. Just those few references can throw them off track and they focus on that and forget the content". The university's formal learning and assessment mechanisms can distract students from real learning by becoming the focus of their attention and efforts. As Kershree says, "There is a lot of emphasis [by the students] on reading and writing, doing the assignment, and not actually reading [so] that you are learning along the way. [...] I think that hampers learning and picking up the skill because they are more focused on passing, getting through the year". Kershree notes that often students have the necessary literacy skills but "are not sure of themselves". When they do have poor literacy skills, they experience this lack as a personal failing. Maureen says, "I think that is the biggest hindrance for people using the writing centre, that sense of shame that 'I don't have the skills to do that'". She 
perceives the students as initially struggling with group work because they find it "too exposing". This shame reveals just how pervasive the hegemonic claims of dominant academic Discourses are, with the students on their first encounter with these Discourses immediately experiencing themselves as deficient. The second space of the university positions them as disadvantaged intellectually because they lack the necessary academic literacy skills (Smit 2012: 372, Widin 2018, Wilmot and McKenna 2018), and their fear reflects this.

The way the tutors counter the students' fear is through third space, drawing on the students' funds of knowledge to both scaffold learning and equip the students with navigational skills. Kershree explicitly locates this support outside the second space of academic literacy instruction by calling it "emotional reassurance". The tutors - arguably because they are already more firmly established in the second space of university Discourses, and so do not fear them - can open a third space that allows students to bypass bottlenecks such as referencing. Maureen and Sharon specifically describe exercises that affirm the students' funds of knowledge and skills as means of scaffolding their access to and confidence with university knowledge. Maureen uses group talk, moving the locus of discussion away from university Discourses that are framed by literacy requirements the students find inhibiting: "Once you begin to talk and say, forget about reading, just think about what do you know about this topic from what you have just heard, just general knowledge?". Similarly, Sharon uses free writing: "Sometimes students get overwhelmed [...] and when you say to them, 'Just close the book and write anything on a related topic', they [are] actually surprised - they were in the lecture, they did listen [...] That is always a winning for me". Here, the third space functions in Moje et al.'s (2004: 44) first sense, scaffolding, by providing "opportunities for success in traditional school learning while also making a space for typically marginalised voices". Students who were literally silenced by the artificiality of academic literacy conventions are given permission to forget these conventions momentarily, and regain confidence so that they re-engage with the content they are learning.

In this third space, process is more important than product, and the tutors take the students seriously as agents engaged in actively negotiating between their various funds of knowledge. Maureen talks of teaching her group to use the term "frontier words" to describe vocabulary in a reading that is just beyond their understanding but which they can guess the meaning of. The students gain a vocabulary for naming - and so, owning - their learning experiences, gaining control over their academic literacy and its development. Rather than hiding their ignorance of dominant Discourse as shameful, they bring this Discourse into the discursive space of the tutorial so that they can explicitly map it.

As a consequence of South Africa's cultural diversity, the third space of the WURU tutorials is particularly complex, with students' everyday funds of knowledge and Discourses mapping across different class, cultural, linguistic, and religious backgrounds. This diversity means that students encounter unfamiliar funds of knowledge not only in their classwork, but also in their interactions with classmates from different backgrounds. This can be uncomfortable, given that South African society still tends to be highly segregated along ethnic and economic grounds as a legacy of its history of colonisation and apartheid. Moje et al. (2004: 44) stress that the kind of change that can occur in third space involves challenging and reshaping not only dominant academic Discourses and knowledges, but also the students' own everyday funds. The interactions in the tutorial space, which encourage students from different sectors of society to learn about and with each other, have the potential therefore to contribute to wider social change in South Africa's political development. As a peer-led space, the tutorial can host discussions about subjects that would be too politically 
charged for the lecture hall. For example, Liezel mentions drawing her students' racial and religious identities into group discussion about the students" "teaching experience" (a work-experience placement the students fulfil in each year of their degree), leading to what she experiences as "wonderful debate". Her sense of the function of the WURU space clearly extends far beyond academic literacy in any strict sense, but rather includes broadening the students' narratives of race and identity as part of their development: "[race] has been playing on their mind, but I think questions like that stick with them, that will help develop them as students". Such development is hard to quantify in terms of learning outcomes or curriculum transformation, but is arguably an illustration of how third space can accommodate a range of discourses and positionings, and so create rich opportunities for collective thought and learning out of possible conflict and differences, as Gutiérrez et al. (1995) argue.

Yet this example from Liezel's class is not the norm. The deeply-engrained social divisions created by centuries of colonisation and segregation are not simple to overcome in the university's social spaces or in the individual student's identity narratives. Although, as discussed above, the tutors do work to rewrite deficit discourses, they also struggle to successfully negotiate the positionings these discourses impose upon them and their students. In their conversation, the peer tutors reveal the belief that they have to choose between investing in dominant Discourses - as this will bring them academic and so economic success - and challenging these Discourses as unjust.

\subsection{Post-colonial "splitting": The apparent choice between access and transformation}

The tutors are deeply invested in the students' success. In the previous section, we noted that the tutors rewrite the deficit discourse; another way to say this is that they move the focus away from the skills the students supposedly lack, and instead look at how they rewrite their identity narratives. When students negotiate and renegotiate new ways of learning or understanding, in the process they develop new academic identities (Archer 2012). The students gain a narrative of agency: Liezel defines success in her group as when, "I think they have improved, their reading has improved and their writing has improved, and they feel that as well" (emphasis added). She describes using discovery questions until the students "come to the conclusion themselves and they don't need feedback and they come to a glory moment". This "glory moment" is not just a moment of logical insight, but also the emerging of a new self, as the student gains confidence in her ability to think in academically accepted ways, and experiences a sense of fit between her identity and that of The Student. Another metaphor the tutors use for this shift in identity is that of ownership of knowledge. Kershree says students have to understand the work by transferring it into their own practical contexts, "making it their own". Paballo agrees, reiterating the phrase "making it their own". These two different phrasings used by the tutors suggest conflicting interpretations of the negotiation the students perform; while Kershree and Paballo's metaphor of "ownership" suggests that the students draw what they are learning into their own funds of knowledge through the scaffolding of third space, Liezel's description of "improved" reading and writing suggests continued investment in the status of dominant academic Discourses as superior to and more valuable than other funds of knowledge. In their collective third space, the students and tutors have not managed to evade the positionalities constructed for them by the wider discursive and material structures of South Africa's political and socio-economic reality. Gutiérrez (2008: 149) argues that a collective third space is fully achieved when "traditional conceptions of academic literacy and instruction for students from nondominant communities are contested and replaced with forms of literacy 
that privilege and are contingent upon students' sociohistorical lives, both proximally and distally". Arguably, it is precisely the WURU students' socio-historical lives that prevent them from contesting the dominant Discourses as Gutiérrez envisions.

In other words, what academic success means for students - and so the status accorded by them to the Discourses that ensure this success - has to be considered when analysing their thirdspace negotiations of identity. The B.Ed. programme attracts some of the poorest students in South Africa because it has among the lowest entry requirements for university degrees, and because it is preferentially funded by the government in the form of bursaries from the National Student Financial Aid Scheme (NSFAS), a government body formed to "support [t] access to, and success in, higher education and training for students from poor and working class families who would otherwise not be able to afford to study" (NSFAS n.d.). A university degree represents employment and a way out of poverty, often not just for students as individuals but for their extended families as well. One anecdote told by Maureen reveals how academic literacy (as a dominant Discourse) becomes entangled in the students' narratives; they conflate poverty with rural backwardness and ignorance, and set it over against the university as an urban, cosmopolitan space: "In my first group, I don't know, maybe 'cos they all come from the same place, they hyped on this idea of coming from very poor background. I think also being overwhelmed by the city and culture of [the university] and just the sense of the whole different environment, and I think that worked on them and against confidence - just general fitting into the university space". The students cling to their identity as economically, and so educationally, disadvantaged to explain their struggles with the foreign Discourses of academic literacy, to help them manage the shame of lacking access to the dominant Discourses and practices that keep the gate to the middle-class future they desire. They have not yet reached a productive third space in which "people are not constantly defined in relation to a dominant Discourse [...] a productive hybrid cultural space, rather than a fragmented and angst-ridden psychological space" (Moje et al. 2004: 43).

The tutors themselves, perhaps because they are surer of academic success, are beginning to question the dominance of established academic literacy Discourses, as discussed above, but even they are still heavily invested in these Discourses. They show "post-colonial splitting" (Bhabha 1994: 98-99, 131) "of discourse, culture, and consciousness, in which students both take up and resist the privileged language of academic contexts" (Moje et al. 2004: 43). They are aware of what academic success can bring them, and so an important thread in their perception of themselves is as possessing the academic literacy skills that can help guarantee success. Paballo, for example, describes her work at the centre in instrumental terms, as helping improve her academic literacy and so helping her, in her words, get "where I want to go" (our emphasis). Similarly, though Sharon's first reason for wanting to improve her skills is so that she can help her group more effectively, her second is that she may also benefit from her gain in skills. The tutors have realised that gaining access to dominant academic Discourses increases their social mobility, and so they "take up [this] privileged language of academic contexts" (Moje et al. 2004: 43). This investment in dominant Discourses exists alongside the nascent resistance to these Discourses discussed above, arising from the tutors' realisation that instead of enabling the students' expression of higher order knowledge and thinking, mainstream academic Discourses can instead be a barrier to real learning and academic achievement. Moje et al. (2004: 42) note that 'being 'in-between' several different funds of knowledge and Discourse can be both productive and constraining in terms of one's literate, social and cultural practices - and, ultimately, one's identity development". The tutors seem to experience a sense of both agency 
and constraint as they negotiate their roles as peers who induct fellow students into the academic Discourses that simultaneously empower and oppress them all.

The peer tutors also experience constraint due to another facet of their in-betweenness, which is their ambiguous position as students who also hold teaching positions within the university's official structures. The tutors have a sense of ownership of WURU and the writing centre. They have invested in its mission to support students, and envision a continued and expanded role for it as embedded in all of the B.Ed. courses all the way through the degree programme. However, the status of the WURU space as parallel and adjacent to official second space, and the unofficial status of the tutors as peer tutors, place limitations on what the tutorials can achieve. The tutors share a strong sense of marginalisation, of not being understood or taken seriously by lecturers or university managers. They sense a failure to invest in academic support on the part of the university mainstream. Paballo uses a metaphor of physical isolation, saying, "It is like the writing centre is not one of the structures of the university". Liezel says bitterly, "Actually they [managers] don't want anything to do with it. I have never seen them involved or promote it at university". Kershree talks of how lecturers do not take seriously the tutors' feedback about students' needs and preferences, even though the tutors are the ones who have "direct interface with the students". Kershree here describes the shutting down of third space, and denial of any kind of official status to the alternative funds of knowledge and Discourse uncovered or generated in the tutorials. The tutors' experience reveals how firmly established the traditional hierarchies of academic Discourses are, controlling "the social organisation of learning and what counts as knowledge" (Gutiérrez 2008: 152). There is little that the tutors can do to overcome this constraint, given their subordinate position within this organisation.

\section{Conclusion}

The tutors' discursive reconstruction of the WURU intervention, analysed as third space, reveals the enormous potential of such space for empowering students from non-dominant cultures, not only in terms of aiding their epistemological access to dominant academic knowledges and Discourses, but also - with more profound implications for long-term emancipation and social change - opening the way for first experimental steps towards real decolonial transformation of these knowledges and Discourses. The tutors and students together draw on both academic and everyday funds of knowledge, to create space that scaffolds learning, builds navigational skills, and opens ways to transformation. The tutors' words also reveal how the strain of working in-between these funds can be inhibiting rather than generative, resulting in "post-colonial splitting" (Bhabha 1994). Our findings suggest how impoverished official university moves toward transformation are by the exclusion of students' peer funds of knowledge, generated not only in the first spaces of our diverse student body, but also at the "cultural interface" (Nakata et al. 2014) between marginalised and dominant Discourses. In order to engage meaningfully with the academic-support access paradox, and offer the kind of academic support envisaged by Wilmot and McKenna (2018) that works to forward transformation and is flexible enough to respond to the ever-changing needs of the diverse student body, it is vital to know more about the stories that are created in-between spaces, and about the processes by which students accept, deny, negotiate, and enjoy their hybrid identities. The insights the tutorial third space generates have to be taken seriously in the conversations we will need to have around access to knowledge, academic literacy practices, and reading and writing as social practices if South Africa's universities are to transform. 


\section{References}

Archer A. 2012. Changing academic landscapes: Principles and practices of teaching writing at the University of Cape Town. In C. Thaiss, G. Bräuer, P. Carlino, L. Ganobcsik-Williams and A. Sinha (eds.) Writing programs worldwide: Profiles of academic writing in many places. Colorado: Parlor Press/WAC Clearinghouse. pp. 353-364.

Bhabha, H. 1994. The location of culture. London: Routledge.

Boughey, C. 2002. 'Naming' students' problems: An analysis of language-related discourses at a South African university. Teaching in Higher Education 7(3): 295-307. https://doi.org/10.1080/13562510220144798

Boughey, C. and S. McKenna. 2016. Academic literacy and the decontextualised learner. Critical Studies in Teaching and Learning 4(2): 1-9.

Butler, G. 2013. Discipline-specific versus generic academic literacy intervention for university education: An issue of impact? Journal for Language Teaching 47(2): 71-88. https://doi.org/10.4314/jlt.v47i2.4

Carstens, A. 2013. Collaboration as the key to the integration of language and content in academic literacy interventions. South African Journal for Language Teaching 47(2): 109-126. https://doi.org/10.4314/jlt.v47i2.6

Carter, S. 2009. The writing centre paradox: Talk about legitimacy and the problem of institutional change. College Composition and Communication 61(1): 133-152.

Clarence, S. and S. McKenna. 2017. Developing academic literacies through understanding the nature of disciplinary knowledge. London Review of Education 15(1): 38-49. https://doi.org/10.18546//re.15.1.04

Cohen, L., L. Manion and K. Morrison. 2018. Research methods in education. Abingdon, UK: Routledge.

Coleman, L. 2016. Offsetting deficit conceptualisations: Methodological considerations for higher education research. Critical Studies in Teaching and Learning 4(1): 16-38. https://doi.org/10.14426/cristal.v4i1.59

Dison, L. and B. Mendelowitz. 2017. Reflecting on writing centre practice through students' experiences of a contextualised writing centre. In L. Dison and S. Clarence (eds.) Writing centres in higher education: Working in and across the disciplines. Bloemfontein: Afrisun Media. pp. 193-208. https://doi.org/10.18820/9781928357551

English, L. 2005. Third-space practitioners: Women educating for justice in the global south. Adult Education Quarterly 55(2): 85-100. https://doi.org/10.1177/0741713604271851

Gee, J.P. 1996. Social linguistics and literacies: Ideology in discourses. London: Taylor and Francis. 
Griffiths, D. 2019. \#FeesMustFall and the decolonised university in South Africa: Tensions and opportunities in a globalising world. International Journal of Educational Research 94: 143-149. https://doi.org/10.1016/j.ijer.2019.01.004

Gutiérrez, K. 2008. Developing sociocritical literacy in the third space. Reading Research Quarterly 43(2): 148-164. https://doi.org/10.1598/rrq.43.2.3

Gutiérrez, K., P. Baquedano-Lopez, H. Alvarez and M. Chiu. 1999. Building a culture of collaboration through hybrid language practices. Theory into Practice 38(2): 87-93. https://doi.org/10.1080/00405849909543837

Gutiérrez, K., P. Baquedano-Lopez and C. Tejeda. 1999. Rethinking diversity: Hybridity and hybrid language practices in the third space. Mind, Culture and Activity 6(4): 286-303. https://doi.org/10.1080/10749039909524733

Gutiérrez, K., B. Rymes and J. Larson. 1995. Script, counter script, and underlife in the classroom: James Brown versus Brown v. Board of Education. Harvard Educational Review 65(3): 445-471. https://doi.org/10.17763/haer.65.3.r16146n25h4mh384

Haggis, T. 2003. Constructing images of ourselves? A critical investigation into approaches to learning research in higher education. British Educational Research Journal 29(1): 89-104. https://doi.org/10.1080/0141192032000057401

Hall, S. 1997. The spectacle of the other. In S. Hall (ed.) Representation: Cultural representation and signifying practices. London: Sage. pp. 225-279.

Hutchings, K. 2006. Reaching students: Lessons from a writing centre. Higher Education Research and Development 25(3): 247-261. https://doi.org/10.1080/07294360600793002

Janks, H. 2004. The access paradox. English in Australia 139: 33-42.

Lea, M. and B. Street. 1998. Student writing in higher education: An academic literacies approach. Studies in Higher Education 23(2): 157-173. https://doi.org/10.1080/030750798 $\underline{12331380364}$

Lea, M. and B. Street. 2000. Student writing and staff feedback in higher education: An academic literacies approach. In M. Lea and B. Street (eds.) Student writing in higher education: New contexts. Buckingham: Open University Press. pp. 33-46.

Lea, M. and B. Street. 2006. The 'academic literacies' model: Theory and applications. Theory into Practice 454(4): 368-377.

Lillis, T. and J. Turner. 2001. Student writing in higher education: Contemporary confusion, traditional concerns. Teaching in Higher Education 61(1): 57-68. https://doi.org/10.1080/ $\underline{13562510020029608}$

Mills, K.A. and B. Comber. 2013. Space, place and power: The spatial turn in literacy research. In K. Hall, T. Cremin, B. Comber and L. Moll (eds.) International handbook of research in 
children's literacy, learning and culture. London: Wiley-Blackwell. pp. 412-423. https:// doi.org/10.1002/9781118323342.ch30

Moje, E.B., M. Ciechanowski, K. Kramer, L. Ellis, R. Carillo and T. Collazo. 2004. Working toward third space in content area literacy: An examination of everyday funds of knowledge and discourse. Reading Research Quarterly 39(1): 38-70. https://doi.org/10.1598/rrq.39.1.4

Moje, E.B. 2013. Hybrid literacies in a post-hybrid world: Making a case for navigating. In K. Hall, T. Cremin, B. Comber and L. Moll (eds.) International handbook of research in children's literacy, learning and culture. London: Wiley-Blackwell. pp. 359-372. https://doi.org/ $\underline{10.1002 / 9781118323342 . \operatorname{ch} 26}$

Morrow, W. 1994. Entitlement and achievement in education. Studies in Philosophy and Education 13(1): 33-47.

Nakata, M., V. Nakata, S. Keech and R. Bolt. 2014. Decolonial goals and pedagogies for Indigenous Studies. Decolonisation: Indigeneity, Education and Society 1(1): 120-140.

NSFAS. n.d. Our mission. Available online: http://www.nsfas.org.za/content/mission.html (Accessed 8 May 2019).

Paxton, M. 2007. Students' interim literacies as a dynamic resource for teaching and transformation. Southern African Linguistics and Applied Language Studies 25(1): 45-55. https://doi.org/10.2989/16073610709486445

Smit, R. 2012. Towards a clearer understanding of student disadvantage in higher education: Problematising deficit thinking. Higher Education Research and Development 313(3): 369-380. https://doi.org/10.1080/07294360.2011.634383

Soja, E.W. 1996. Thirdspace: Journeys to Los Angeles and other real-and-imagined places. Oxford: Blackwell Publishers.

Street, B. 2003. What's "new" in New Literacy Studies? Critical approaches to literacy in theory and practice. Current Issues in Comparative Education 52(2): 77-91.

Street, B. 2006. Autonomous and ideological models of literacy: Approaches from New Literacy studies. Available online: http://www.philbu.net/media-anthropology/street_newliteracy.pdf (Accessed 12 November 2012).

Van Schalkwyk, S.C. 2008. Acquiring Academic Literacy: A Case of First-Year Extended Degree Programme Students at Stellenbosch University. Unpublished PhD dissertation, Stellenbosch University.

Vygotsky, L.S. 1978. Mind in society: The development of higher psychological processes. Cambridge, MA: Harvard University Press.

Wellington, J. 2015. Educational research. London: Bloomsbury Academic. 
Widin, J. 2018. Academic literacy support: Challenging the logic of practice. In J. Albright, D. Hartman and J. Widin (eds.) Bourdieu's field theory and the social sciences. Singapore: Springer Nature. pp. 1-15. https://doi.org/10.1007/978-981-10-5385-6_5

Wilmot, K. and S. McKenna. 2018. Writing groups as transformative spaces. Higher Education Research and Development 37(3): 868-882. https://doi.org/10.1080/07294360.2018.1450361

Wingate, U. 2006. Doing away with "study skills". Teaching in Higher Education 11(4): 457-469. https://doi.org/10.1080/13562510600874268

Wingate, U. 2015. Academic literacy and student diversity: The case for inclusive practice. Bristol: Multilingual Matters.

Wingate, U. and C.A. Dreiss. 2009. Developing students' academic literacy: An online approach. Journal of Academic Language and Learning 3(1): 114-125. 